\title{
Influence of surface residual stresses on the fatigue life and crack propagation behavior of turned Inconel 718 super-alloy
}

\author{
Hamid Javadi ${ }^{1, *}$, Walid Jomaa ${ }^{1}$, Elvi Dalgaard ${ }^{2}$, Myriam Brochu ${ }^{3}$, and Philippe Bocher ${ }^{1}$ \\ ${ }^{1}$ Ecole de Technologie Supérieure, Mechanical Engineering Department, 1100 Rue Notre-Dame Ouest, Montréal, H3C 1K3, \\ Québec, Canada \\ ${ }^{2}$ Pratt \& Whitney Canada, 1000 Rue Marie-Victorin, Longueuil, J4G 1A1, Québec, Canada \\ ${ }^{3}$ Ecole Polytechnique de Montréal, Mechanical Engineering Department, 2900 Boulevard Edouard-Montpetit, Montréal, \\ H3T 1J4, Québec, Canada
}

\begin{abstract}
The effects of surface roughness parameters and residual stresses induced by finish turning on fatigue life and crack propagation behavior of Inconel 718 super-alloy are investigated. A criterion serving as a good indicator of surface quality is also discovered. This is carried out for some specific turning conditions in order to control surface characteristics including surface roughness and the bi-axial state of surface residual stresses and to investigate the effects of these characteristics on fatigue behavior. Rotating bending fatigue (RBF) tests are performed on the machined specimens at room temperature. Characterization techniques including X-ray diffraction (XRD), laser confocal microscopy, and opto-digital microscopy are used to investigate surface residual stresses in axial (ARS) and hoop (HRS) directions, surface roughness, and secondary fatigue cracks, respectively. The huge dispersion in fatigue life of smooth turned Inconel 718 with very low arithmetic average roughness $(\mathrm{Ra})$ values indicates that surface finishing is not the only reliable criterion for quality control of machined components. Multivariate statistical analyses show that axial surface residual stress is the most important surface characteristic affecting the fatigue life of machined Inconel 718 for the conditions tested. Changing ARS from compressive to tensile increases the number of secondary cracks and also decreases the fatigue life of turned specimens.
\end{abstract}

\section{INTRODUCTION}

In today's aerospace industry, the main concerns include achieving an optimum, reliable, and reproducible manufacturing process with high predictability of component service life at the lowest production cost. Owing to their excellent mechanical properties at elevated temperatures, nickel-based super-alloys are commonly used to manufacture the hottest parts in aircraft engines by a share of over half by weight [1]. Some critical parts in engine hot compartments such as gas turbine disks are made of Inconel 718 super-alloy, which is arguably the most popular precipitationhardened alloy in this class [2]. The manufacturing of these components involves various machining processes, namely milling, turning, and drilling, and each may have multiple steps, including roughing, semi-finishing, and finishing. It is known that finish machining operations significantly affect the surface integrity characteristics of Inconel 718 [2,3]. Some of the main aspects of these alterations are topographical (surface finish), mechanical (residual stresses, plastic deformation), and thermal (material softening) [4-9].

Several studies have focused on the effects of machining processes on surface integrity of super-alloys [10-12]. Others have investigated the effects of surface integrity on fatigue lives of machined components [13-15]. Surface finish, in particular the arithmetic average roughness $(\mathrm{Ra})$, is considered the main quality control criterion for manufacturing components. In the aerospace industry, Ra should be below $1 \mu \mathrm{m}$ after the final machining steps for some critical parts [16]. Other surface integrity aspects such as residual stresses were found to have a significant effect on the fatigue lives of machined components [13, 17-19]. In particular, the low thermal conductivity and high strain rate sensitivity of Inconel 718 favor the generation of high-magnitude tensile residual stresses at the surface and deteriorate fatigue life considerably $[13,20]$.

It appears that, although it is the main machining process used in the manufacturing of rotating parts such as turbine disks, the effects of turning-induced surface integrity on the fatigue life of Inconel 718 have not been investigated and understood thoroughly. In the current paper, an analysis of rotating bending fatigue upon turned Inconel 718 superalloy is performed. To do so, fatigue specimens were carefully machined in order to produce various surface integrity characteristics while keeping arithmetic average roughness (Ra) below $1 \mu \mathrm{m}$. The main purpose of the present study is to find out which surface characteristics concerning surface roughness and residual stresses are the most influential

\footnotetext{
* Corresponding author: hamid.javadi.1@ens.etsmtl.ca
} 
to fatigue life of turned Inconel 718 components with emphasis on fatigue crack behavior.

\section{MATERIALS \& METHODS}

Fatigue specimens were made from $12 \mathrm{~mm}$ diameter Inconel 718 bars. The generic chemical composition of the Inconel 718 super-alloy is as follows: Ni-19Cr-18Fe$5 \mathrm{Nb}-3 \mathrm{Mo}-0.9 \mathrm{Ti}-0.5 \mathrm{Al}$ (wt. \%). Before machining, the bars were solution treated and aged to reach a hardness of $41 \pm 1 \mathrm{HRC}$ and an average grain size of $25 \mu \mathrm{m}$. Rotating bending fatigue (RBF) specimens were machined by turning to produce the part in Figure 1 . With this geometry, the entire length of the gage section (approximately $25 \mathrm{~mm}$ long) was stressed uniformly during fatigue tests. This latter is particularly useful for studying secondary fatigue cracks on the gage section, because the odds of crack nucleation are uniform for the whole length. Rotating bending fatigue (RBF) tests with a stress ratio $R=-1$ were performed at room temperature using a R.R. MOORE machine from INSTRON (SATP1962) under a stress amplitude of $448 \mathrm{MPa}$ and a frequency of $30 \mathrm{~Hz}$. Some selected fatigue specimens were mechanically fine-polished in order to remove machining-induced surface integrity and thereby evaluate the fatigue behavior of the bulk material (reference condition). Three finishing turning conditions were selected (Table 1) to produce multiple residual stress values in both the axial and hoop directions while keeping an arithmetic average roughness ( $\mathrm{Ra}$ ) below $1 \mu \mathrm{m}$. Four replications were machined for each turning condition in order to repeat fatigue tests and perform surface integrity characterizations.

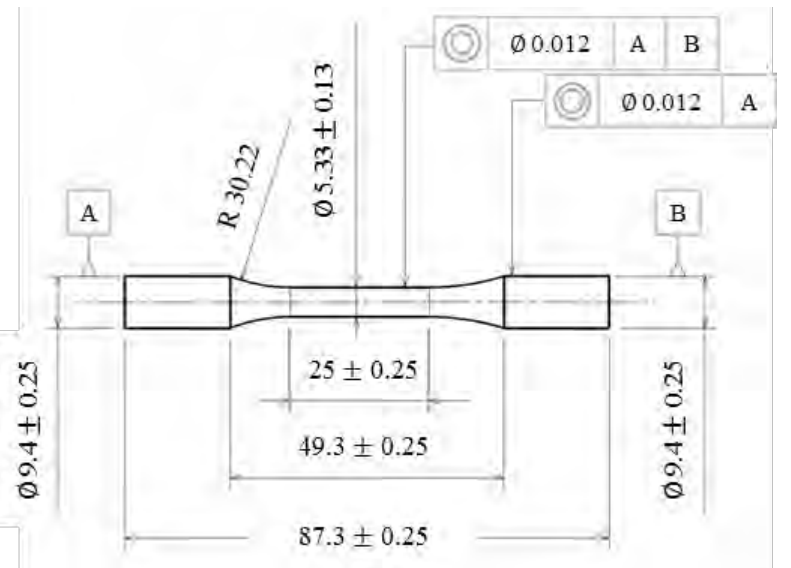

Fig. 1. Geometry of the straight-shank rotating bending fatigue (RBF) specimens (all in $\mathrm{mm}$ ).
A laser confocal microscope LEXT OLS4100 from OLYMPUS was used to measure surface roughness parameters including maximum height of the roughness profile (Rt) and arithmetic average roughness (Ra) parameters. The residual stresses were measured using the X-ray diffraction technique according to $\sin ^{2} \psi$ method with Proto iXRD1 system. In these measurements, lattice plane [311] was selected along with a Mn tube. Secondary cracks were observed on broken specimens using opto-digital microscope DSX500 from OLYMPUS.

\section{RESULTS \& DISCUSSION}

Surface integrity characteristics and fatigue lives are displayed in Table 2. The industrial surface finishing criterion was met for all the conditions, as the arithmetic average roughness $(\mathrm{Ra})$ was in all cases below $1 \mu \mathrm{m}$. A noticeable difference was observed in axial residual stress (ARS) for these low-roughness machined surfaces. Although arithmetic average roughness is kept below $1 \mu \mathrm{m}$, significant variation in $\mathrm{Ra}$ is also observed (from 0.02 to $0.74 \mu \mathrm{m}$ ). Hence, one can suspect that fatigue life can be influenced by the combined effects of surface roughness and residual stresses. Polishing the specimens further reduced the roughness $(\mathrm{Ra}=0.02 \mu \mathrm{m})$. Polishing also successfully decreased the level of residual stresses and produced a free-stress surface resulting in a target fatigue life of $10^{6}$ cycles.

In order to verify which of the two investigated surface integrity characteristics dominates fatigue life, a multivariate analysis was performed on the fatigue lives. A partial correlation matrix (Figure 2) was produced in which the correlation coefficient between two features is determined without considering the influences of the other characteristics [21]. The rule of thumb is the closer coefficient of correlation values to 1 or -1 , the higher correlations exist between two characteristics, while values around zero means there is no linear correlation between the characteristics.

Figure 2 shows that among the surface integrity characteristics investigated, the axial residual stress had the greatest correlation with fatigue life $(-0.61)$ while the hoop residual stress (HRS) and surface roughness parameters ( $\mathrm{Ra} \& \mathrm{Rt}$ ) had the lowest correlation coefficients (smaller than 0.5). Thus, under the experimental conditions investigated in the present study, the roughness parameters have less effect on the fatigue life of turned Inconel 718 than axial residual

Table 1. The surface conditions studied.

\begin{tabular}{|c|c|c|c|c|c|}
\hline \multirow{2}{*}{ Run\# } & \multicolumn{3}{|c|}{ Cutting parameters } & \multicolumn{2}{c|}{ No. of specimens } \\
\cline { 2 - 6 } & $\begin{array}{c}\text { Cutting speed } \\
\text { S(m/min) }\end{array}$ & $\begin{array}{c}\text { Feed rate } \\
f(\mathrm{~mm} / \mathrm{rev})\end{array}$ & $\begin{array}{c}\text { Depth of cut } \\
d(\mathrm{~mm})\end{array}$ & $\begin{array}{c}\text { Fatigue } \\
\text { tests }\end{array}$ & $\begin{array}{c}\text { Surface } \\
\text { characterization }\end{array}$ \\
\hline Machined run \#1 & 67 & 0.020 & 0.300 & 3 & 4 \\
\hline Machined run \#2 & 89 & 0.098 & 0.230 & 3 & 4 \\
\hline Machined run \#3 & 49 & 0.051 & 0.127 & 3 & 4 \\
\hline Polished & - & - & - & 3 & 4 \\
\hline
\end{tabular}


Table 2. Average values (four replications) of surface roughness, residual stresses, and average fatigue lives (three RBF tests) for the selected turning conditions and the polished specimens.

\begin{tabular}{|c|c|c|c|c|c|}
\hline \multirow{2}{*}{ Run\# } & \multicolumn{2}{|c|}{ Surface roughness } & \multicolumn{2}{c|}{ Surface residual stresses } & Fatigue life \\
\cline { 2 - 5 } & $R a(\mu \mathrm{m})$ & $R t(\mu \mathrm{m})$ & Axial $(\mathrm{MPa})$ & Hoop $(\mathrm{MPa})$ & Nf(Cycles) \\
\hline Machined run \#1 & $0.47 \pm 0.11$ & $4.51 \pm 0.73$ & $-275 \pm 25$ & $492 \pm 28$ & $1.85 \times 10^{6}$ \\
\hline Machined run \#2 & $0.74 \pm 0.13$ & $4.84 \pm 1.38$ & $853 \pm 32$ & $996 \pm 39$ & $5.02 \times 10^{5}$ \\
\hline Machined run \#3 & $0.28 \pm 0.05$ & $2.8 \pm 0.32$ & $146 \pm 28$ & $515 \pm 22$ & $8.33 \times 10^{5}$ \\
\hline Polished & $0.020 \pm 0.002$ & $0.27 \pm 0.05$ & $-9 \pm 30$ & $-3 \pm 43$ & $9.85 \times 10^{5}$ \\
\hline
\end{tabular}

stresses. Likewise, hoop residual stress is also less significant to fatigue life. It would appear that fatigue life is mainly affected by the axial surface residual stress for the conditions studied.

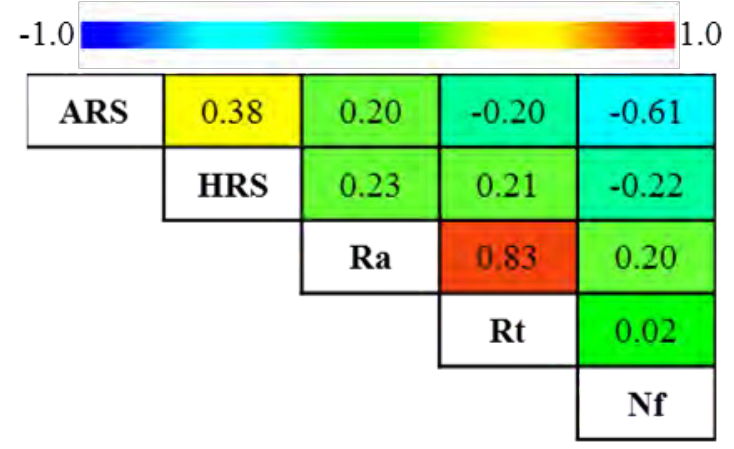

Fig. 2. Partial correlation matrix showing the degree of dependence between various surface characteristics (axial residual stress (ARS), hoop residual stress (HRS), arithmetic average roughness (Ra), and maximum height of the roughness profile (Rt)) and fatigue lives of machined specimens (Nf).
This result can be clearly seen in Figure 3, which depicts fatigue life versus ARS and HRS for all the specimens. Obviously, the greater ARS values diminish the fatigue lives of machined specimens; e.g., when ARS decreases from high tensile (849 $\mathrm{MPa}$ ) to compressive $(-412 \mathrm{MPa})$, the fatigue life is improved from $4.64 \times 10^{5}$ to $2.43 \times 10^{6}$ cycles. To illustrate the importance of ARS, comparing Run 1 and Run 3 with almost the same HRS values confirmed the two-fold increase in fatigue life was due to the compressive ARS for Run 1. On the other hand, the polished specimens had ARS values comparable with Run 3 and their HRS magnitudes were around $500 \mathrm{MPa}$ different. However, their fatigue lives were very comparable, confirming that HRS has less effect on fatigue behavior than does ARS. This confirms the results seen in the partial correlation matrix. It appears that fatigue crack nucleation and propagation are significantly influenced by ARS.

In addition to the main fatigue crack causing the specimens' failures, secondary cracks were observed on the specimens after failure. Figure 4 shows typical secondary fatigue cracks for polished and machined specimens. The secondary crack on a polished surface, shown in Figure 4.a, nucleated on a point with the

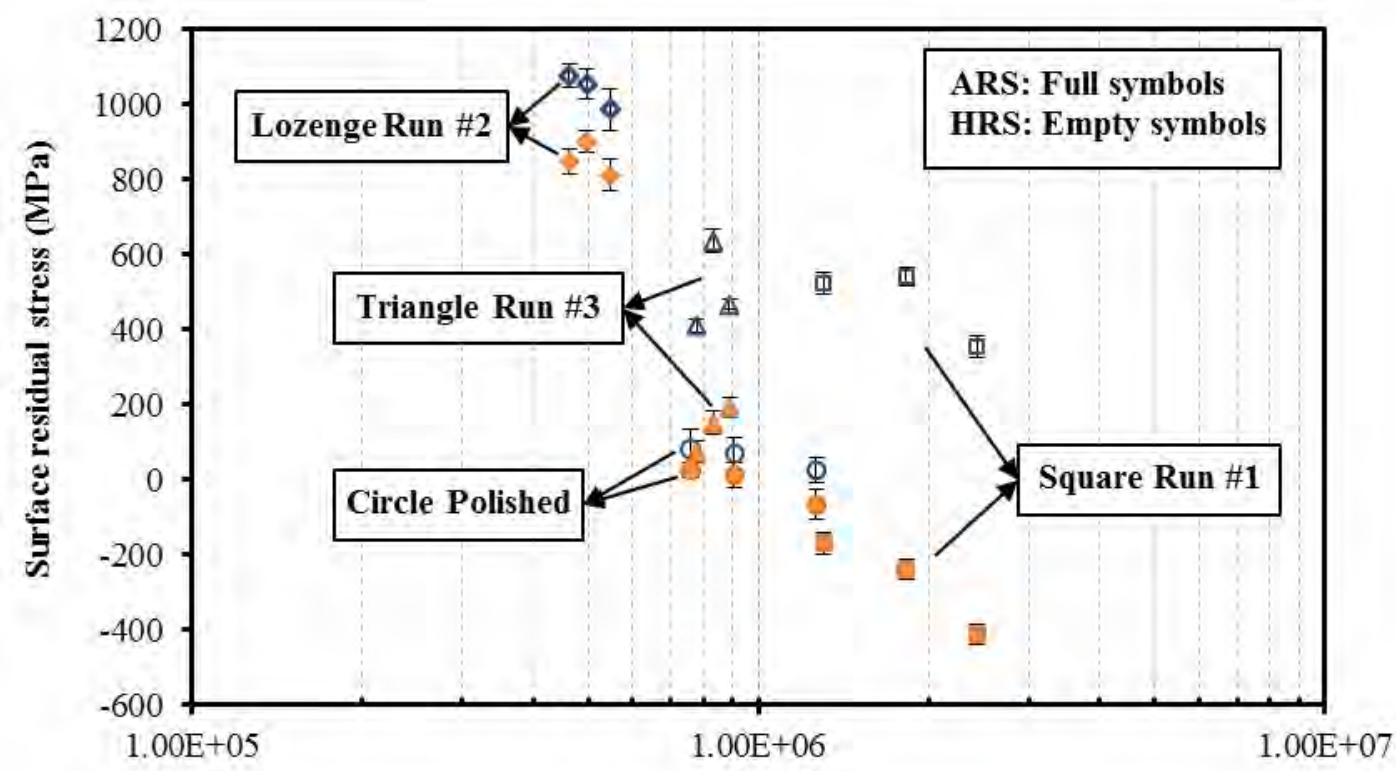

Fatigue life Nf (Cycles)

Fig. 2. Influence of machining-induced residual stresses in axial (full symbols) and hoop (empty symbols) directions on the fatigue lives of machined and polished specimens. 
greatest local stress concentration during the RBF test and propagated in both sides inclined to the applied stress direction. The crack path is hypothetically determined by the crystallographic orientation of the surface grains and their activated slip systems. After passing a few grains (200 to $250 \mu \mathrm{m}$ projected crack length), the crack propagation transited from the short crack to the long crack regime as growth direction became perpendicular to the applied stress. Since the machining-affected layer had been removed, the crack nucleation and propagation were not influenced by surface characteristics for polished specimens; the early stage of crack propagation is considered uniquely microstructure-dependent.

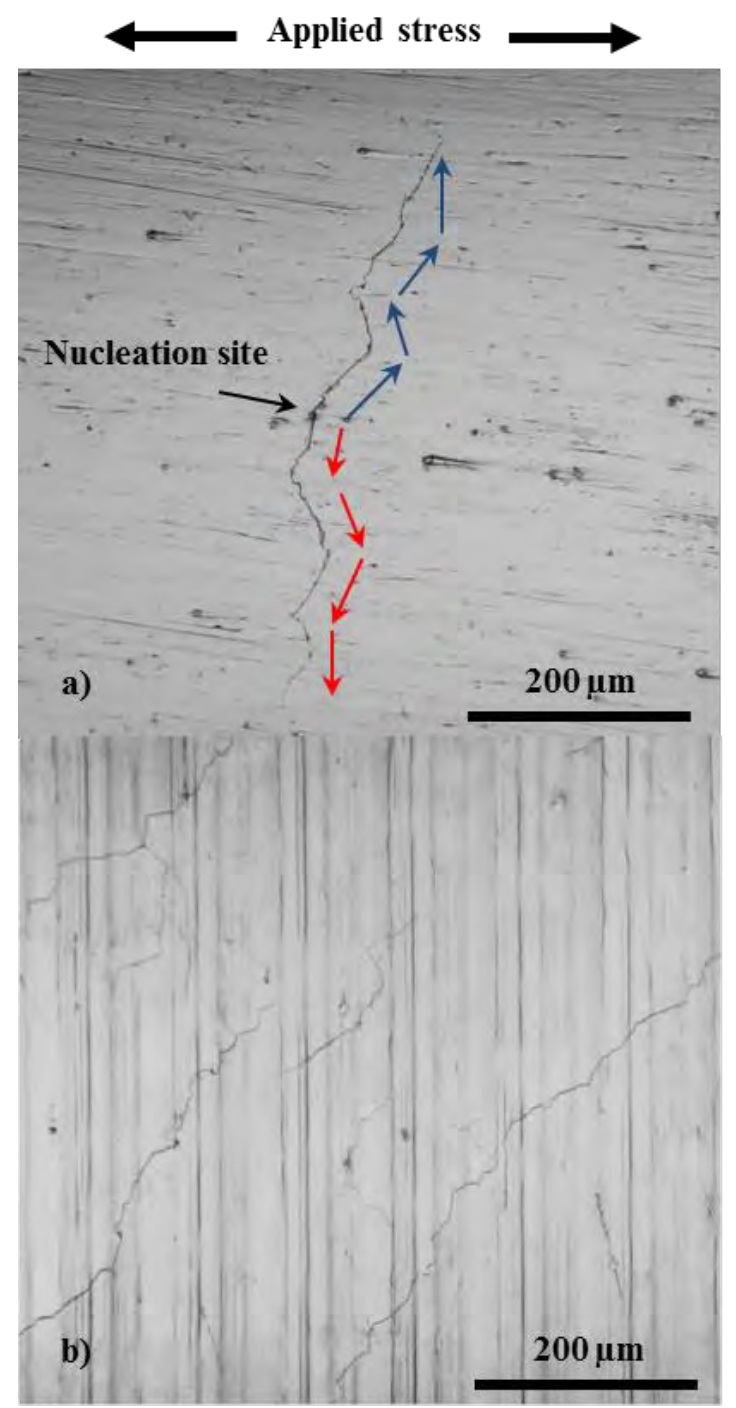

Fig. 4. Typical secondary cracks on fatigue specimens for a) polished and b) machined surfaces.

In contrast, Figure 4.b shows the secondary cracks for a machined surface with high tensile residual stresses (Run 2 ). It was difficult to find the nucleation sites for these cracks since machined surfaces are mainly formed by successive feed marks, scratches, and defects which could be potentially crack nucleation sites. High surface roughness and residual stresses may also act as stress raisers to promote fatigue crack nucleation.

The above cracks always propagated inclined to the loading direction while crossing the parallel feed marks. This may be because of the combined effects from axial and hoop residual stresses, which governs the stress state ahead of the secondary cracks and does not permit their paths to propagate perpendicularly to the loading direction. Moreover, most of these secondary cracks are long enough to be considered as the coalescence of few smaller cracks. It seems that for high tensile residual stresses, the secondary cracks grow faster while skipping the short fatigue crack propagation regime, progressing directly to the long crack regime.

The density of these secondary fatigue cracks was evaluated based on the microscopic observation of the entire gage section surface from a broken specimen ( 2 to 3 specimens per turning condition). The density of secondary fatigue cracks affected the fatigue behavior of the machined specimens; i.e., the greater the number of short cracks, the greater the probability of developing a fatal crack. To illustrate this, for three turning conditions (Runs 1 to 3), the average secondary crack densities were 12,483 , and $62 \mathrm{~cm}^{-2}$ and their average fatigue lives were $1.85 \times 10^{6}, \quad 5.02 \times 10^{5}$, and $8.33 \times 10^{5}$ cycles, respectively. Secondary crack density was minuscule for polished specimens $\left(2 \mathrm{~cm}^{-2}\right)$ due to the low axial residual stress and defect-free surface.

Figure 5 illustrates the influence of machining-induced axial surface residual stresses on the density of secondary fatigue cracks for three selected turning conditions. The compressive stresses of the Run 1 specimen led to a lower secondary crack density and smaller crack size. Conversely, raising the residual stresses to highly tensile values (Run 2) caused a dramatic increase in secondary crack density and also resulted in longer cracks. This indicates that compressive residual stresses delay crack nucleation and short crack propagation.

\section{CONCLUSIONS}

The current study focuses on the effects of residual stresses and surface roughness on fatigue life and crack propagation behavior of turned Inconel 718 super-alloy. The specimens tested were prepared using several finish turning conditions in order to produce various surface residual stresses (from compressive to tensile stresses) while keeping arithmetic average roughness values below $1 \mu \mathrm{m}$ (respecting industrial requirements for critical applications). High cycle fatigue lives $\left(10^{6}\right.$ cycles) were targeted using a rotating bending fatigue (RBF) machine at room temperature with a fixed applied stress (about 40\% yield strength). The results show that: 


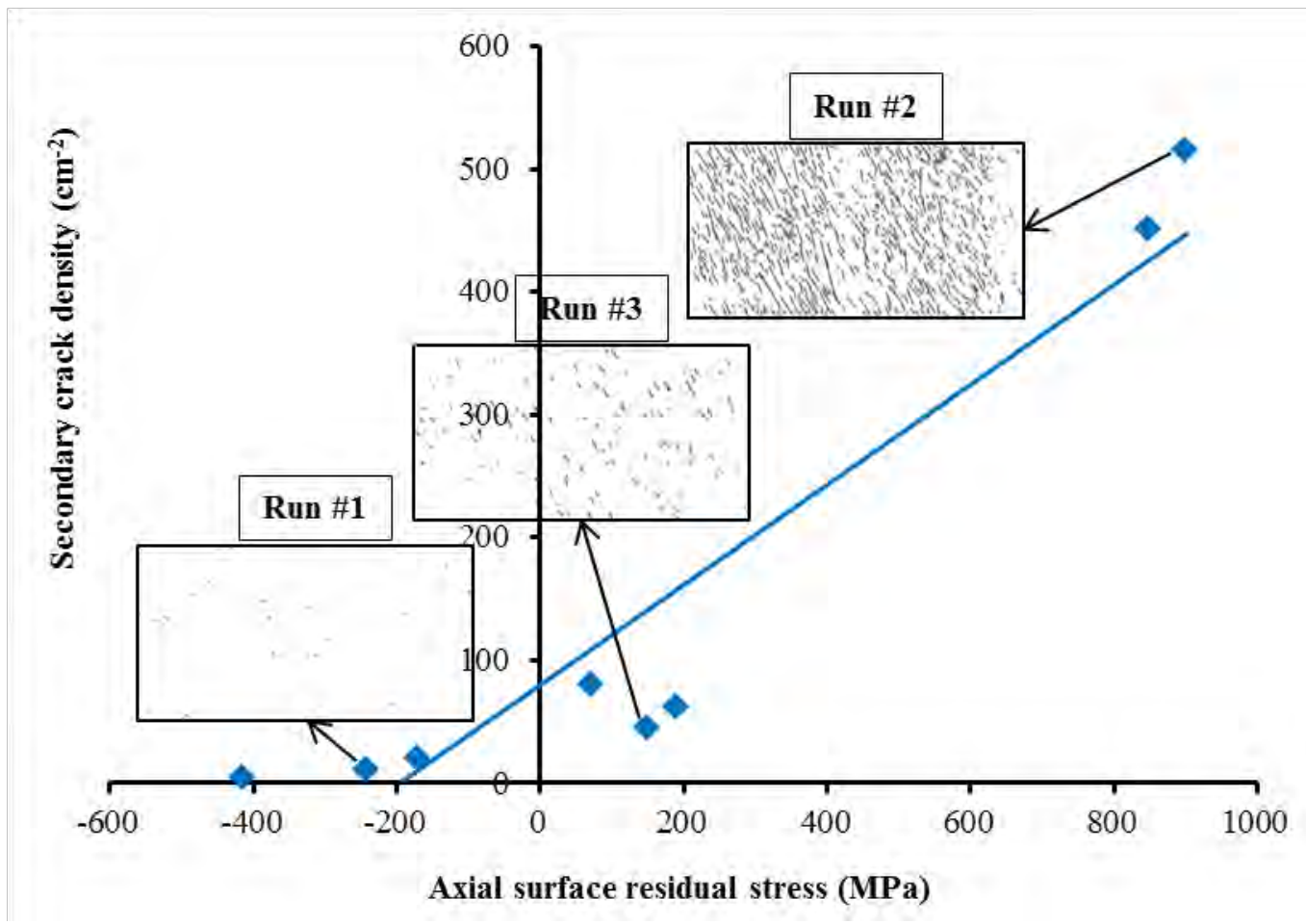

Fig. 5. Dependence of secondary crack densities on the axial surface residual stresses for three highlighted turning conditions by their secondary cracks map representation.

1- Elevated tensile axial surface residual stresses (849 $\mathrm{MPa}$ ) lead to a significant (5-6 fold) reduction in the fatigue lives of the specimens (from $2.43 \times 10^{6}$ to $4.64 \times 10^{5}$ cycles) in comparison with compressive axial surface residual stresses $(-412 \mathrm{MPa})$.

2- It is also found that the secondary crack densities rose with increased surface residual stresses, which supports the fact that compressive residual stresses delayed the crack initiation process, leading to longer fatigue life.

3- Multivariate statistical analysis showed that among the surface integrity characteristics studied, the axial residual stress has the greatest correlation with fatigue life and with crack density, while the arithmetic average roughness $(\mathrm{Ra})$ has the lowest correlation coefficient if kept below a certain threshold.

4- Therefore, surface quality optimizations should be redefined in order to exploit the effect of surface residual stresses rather than surface roughness.

This research has been financially supported by the Natural Sciences and Engineering Research Council of Canada (NSERC) and the Consortium for Research and Innovation in Aerospace in Quebec (CRIAQ) under the project named MANU-510. The authors wish to express their sincere thanks to Pratt \& Whitney Canada and Héroux-Devtek as industrial partners in this project, providing all in-kind materials and their technical and financial support.

\section{REFERENCES}

1. D. Ulutan, T. Ozel, Int. J. Mach. Tools \& Manuf., 51, 250 (2011)

2. R. M'Saoubi, J. Outeiro, H. Chandrasekaran, O. Dillon Jr, Int. J. Sustain. Manuf., 1, 203 (2008)

3. J.P. Davim, Surface Integrity in Machining (Springer, 2010)

4. C. Schlauer, R.L. Peng, M. Odén, Materials Science Forum, 404, 173 (2002)

5. R.M. Arunachalam, M.A. Mannan, A.C. Spowage, Int. J. Mach. Tools \& Manuf., 44, 879 (2004)

6. A.R.C. Sharman, J.I. Hughes, K. Ridgway, J. Mater. Process. Technol., 173, 359 (2006)

7. A. Thakur, S. Gangopadhyay, Int. J. Mach. Tools \& Manuf., 100, 25 (2016)

8. D. Thakur, B. Ramamoorthy, L. Vijayaraghavan, Int. J. Adv. Manuf. Tech., 59, 483 (2012)

9. A.B. Sadat, M.Y. Reddy, B.P. Wang, Int. J. Mech. Sci., 33, 829 (1991)

10. E.O. Ezugwu, Z.M. Wang, C.I. Okeke, Tribol. Trans., 42, 353 (1999)

11. R. Pawade, S.S. Joshi, P. Brahmankar, Int. J. Mach. Tools \& Manuf., 48, 15 (2008)

12. A.R.C. Sharman, J.I. Hughes, K. Ridgway, Mach. Sci. Technol., 8, 399 (2004) 
13. H. Sasahara, Int. J. Mach. Tools \& Manuf., 45, 131 (2005)

14. A. Sharman, D. Aspinwall, R. Dewes, D. Clifton, P. Bowen, Int. J. Mach. Tools \& Manuf., 41, 1681 (2001)

15. S. Bentley, A. Mantle, D. Aspinwall, Intermetallics, 7, 967 (1999)

16. I.O.F. Standardization, ISO 1302: Geometrical Product Specifications (GPS) - Indication of Surface Texture in Technical Product Documentation (ISO, 2002)

17. G. Webster, A. Ezeilo, Int. J. Fatigue., 23, 375 (2001)

18. D. Taylor, O. Clancy, Fatigue Fract. Eng. Mater. Struct., 14, 329 (1991)

19. A. Pramanik, A. Dixit, S. Chattopadhyaya, M. Uddin, Y. Dong, A. Basak, G. Littlefair, Adv. Manuf., 5, 59 (2017)

20. R. M'Saoubi, J. Outeiro, B. Changeux, J. Lebrun, A.M. Dias, J. Mater. Process. Technol., 96, 225 (1999)

21. A.C. Rencher, Methods of Multivariate Analysis (John Wiley \& Sons, 2003) 